Dokuz Eylül Üniversitesi-Mühendislik Fakültesi

Fen ve Mühendislik Dergisi

Cilt 20, Sayı 58, Ocak, 2018
Dokuz Eylul University-Faculty of Engineering Journal of Science and Engineering Volume 20, Issue 58, January, 2018

DOI: $10.21205 /$ deufmd. 2018205814

\title{
Furan Çekirdekli Bileşiklerin Mikrodalga Destekli Molekül İçi Diels Alder Halkalaşma Reaksiyonları
}

\author{
Muhsin KARAARSLAN \\ Aksaray Üniversitesi, Fen Edebiyat Fakültesi, Kimya Bölümü, 68100, Aksaray (ORCID:
} 0000-0002-5928-5990)

(Alınış / Received: 24.04.2017, Kabul / Accepted: 14.11.2017, Online Yayınlanma / Published Online: 20.01.2018)

Anahtar Kelimeler Özet: Bu çalışmada furan çekirdekli bileşiklerin İntra Moleküler İntra Moleküler (Molekül İçi) Diels-Alder (IMDA) halkalaşma reaksiyonu Diels-Alder, mikrodalga yöntemlere gerçekleştirilmiş ve bitişik üç halkalı Furan,

Mikrodalga, Polisiklik, Halka katılması. bileşikler elde edilmiştir. Reaksiyonlar çözücüsüz ortamda ve herhangi bir metal katalizörü kullanmadan gerçekleștirilmiștir. Oksijen yan zincirli başlangıç maddeleri furan çekirdekli bileșiklerin direk alkilasyonu ile elde edilirken, azot yan zincirli başlangıç maddeleri alkilasyondan sonra koruma işlemi yapılarak elde edilmiștir. Halkalașma reaksiyonları için ticari mikrodalga fırın (2450 MHz) kullanılmıștır. Yapılan deneylerin verimleri daha önceden yapılmış olan klasik termal halkalaşma reaksiyonları ile karşılaștırılmıştır. Mikrodalga destekli reaksiyonlardan elde edilen verimlerin termal reaksiyonlardan elde edilen sonuçlarla karşılaștırılabilir nitelikte oldukları sonucuna ulașılmıștır.

\section{Microwave Assisted Intramolecular Diels-Alder Cycloaddition Reaction of Furan Cored Compounds}

\begin{abstract}
Keywords IntraMolecular Diels-Alder, Furan,

Microwave,

Polycyclic Cycloaddition.

Abstract: In this study the Intra Molecular Diels-Alder (IMDA) cycloaddition reactions of the furan cored compounds were carried out by microwave methods to obtain adjacent tricyclic compounds. The reactions were carried out in solvent free environment and without using any metal catalyst. Starting materials with oxygen side chains were obtained by direct alkylation of furan cored compounds, while those materials with nitrogen side chains were obtained by protection after alkylation. A commercial microwave oven $(2450 \mathrm{MHz})$ was used for the cycloaddition reactions. The yields of the experiments were compared with the conventional thermal cyclization reactions. It was concluded that the yields obtained from microwave assisted reactions were comparable to the results obtained from thermal reactions.
\end{abstract}

*Sorumlu yazar: mkaraarslan@aksaray.edu.tr 


\section{Giriş}

İntramoleküler Diels Alder reaksiyonları heteroatom içeren polisiklik halka yapımında en çok kullanılan organik sentez yöntemidir. Bu reaksiyonlarda genellikle dien olarak furan türevi bileşikler kullanılır. [1] Bunun en önemli sebebi furanın tiyofen ve pirole göre daha düşük aromatikliğe sahip olmasıdır. Yine de daha zor reaksiyon veren pirol ve tiyofen türevli bileşikler de diels alder reaksiyonlarında çeşitli ön işlemlerden sonra kullanılabilmektedir [2].

Aminoasitler, aza şekerler ve alkoloidler gibi azot içeren bileșikler ve farmasötik ilaçların büyük bir bölümü azot içeren bileşiklerden oluştuğundan dolayı bu bileşiklerin sentetik olarak sentezi büyük bir önem taşımaktadır.

Yan zincir kısmında (tether de) N-KG ve 0 içeren furan çekirdekli bileşiklerin organik kimyada oldukça zor olan trisiklik ve tetrasiklik fused halkalaşma ürünleri tek adımda Termal ve mikrodalga yöntemle intramoleküler [4+2] Diels-Alder reaksiyonları sonucu elde edilebilmektedir $[3,4]$.

$\mathrm{Bu}$ güne kadar yapılan çalışmalar mikrodalga sentez yönteminin uygun lewis asidi katalizörleride kullanarak daha kısa sürede ve yüksek verimde oluşabildiği sonucunu ortaya koymuştur [5].

Bir diğer önemi ise sentezlenecek materyallerin malzeme bilimi açısından ilginç sonuçlar ortaya çıkarabilme ihtimalidir. Özellikle beş üyeli heteroaromatik bileşiklerle (furan, tiyofen pirol gibi ) gerçekleştirilen reaksiyonlar sonucu oluşan moleküllerin, çeşitli metallerle koordinasyon yaparak nanoyapı özelliğini göstermeleri yeni teknolojileri geliştirebilir. Hedeflenen, trisiklik yapı formları, belli bir düzen ve minimal enerjiye sahip olacaktır.
Ayrıca bünyesinde bulunduracağı heteroatomlarla da koordinasyon yapma potansiyeline sahip olabilecektir [6].

Bu çalışmada daha önce Furan çekirdekli bileşiklerle 1 termal olarak yaptığımız İMDA reaksiyonları uygulaması, mikrodalga yöntem kullanılarak yapılmış ve $\mathbf{2}$ bileşikleri elde edilmiştir. (Şekil 1)

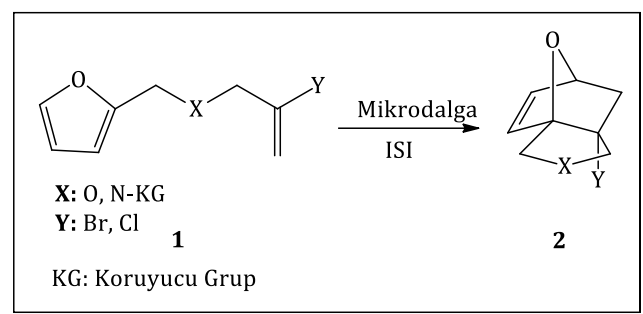

Şekil 1 Genel reaksiyon

İntramoleküler Diels-Alder halkalaşma reaksiyonlarında iki temel esasından biri dien ve denofilin birbirlerine olan ilgilerinin yüksek olması ikincisi ise kolay bir şekilde bir araya gelebileceği bir molekül yapısına sahip olmasıdır. Bunların sonucunda dien ve dienofil arasındaki HOMO-LUMO enerji farkı azalmakta ve halkalaşma verimi artmaktadır [7].

Daha önce yapılan çalışmalarda oksijen yan zincirli moleküllerde oksijen üzerindeki elektron çiftlerinin makas etkisi göstermesi sonucu dien ve dienofilin reaksiyona girdiği görülürken $\mathrm{NH}$ yan zincirli moleküllerde ise bu durumun ancak azotun büyük bir molekül tarafindan korunması sonucu sterik etki vasıtasıyla meydana geldiği görülmüştür [8].

Yaptığımız çalışmada azot atomu fenil fosfat türevli büyük gruplar tarafından korunarak halkalaşma reaksiyonları gerçekleştirilmiştir. 


\section{Materyal ve Metot}

\subsection{Materyal}

Çalışmada kullanılan kimyasal maddeler Merck ve Sigma-Aldrich' den alınmıştır. Çözücüler reaksiyonlarda saf ve kuru olarak kullanılmıștır. Et ${ }_{2} \mathrm{O}$ ve THF metalik sodyum üzerinden benzofenon katalitik indikatörlüğünde kurutuldu. Hegzan (40$60^{\circ} \mathrm{C}$ ) distile edilerek kullanılmıştır. Toluen $\mathrm{CaH}_{2}$ üzerinden kurutularak kullanılmıştır. Kolon kromotografisi için Merck silica gel 60 (0.040-0.063 mm), (0.063-0.200 $\mathrm{mm})$, ince tabaka kromotografisi Merck silika gel 60 GF ile yapılmıștır. Kromotgrafide UV lambası, iyot tankı ve $\mathrm{KMnO}_{4}$ kullanılmıştır. Mikrodalga reaksiyonlar 800 Watt gücünde ticari mikrodalga firında yapılmıştır.

\subsection{Metot}

\subsubsection{Başlangıç maddelerinin sentezi} (1a,1b,4a,4b)

1a, 1b ve 2 nolu başlangıç maddelerinin sentezi daha önceki çalışmalarımızda anlatıldığı şekilde yapılmıştır $[9,10]$.

\section{N-(2-bromoallil)-N-(furan-2-ilmetil)- P-fenilfosfonamidik klorür (4a) :}

Diklorometan (DCM)' da (5mL) çözülmüş fenil fosfonil diklorit (1,69 mmol) üzerine $0^{\circ} \mathrm{C}^{\prime}$ de trietil amin $(5,08 \mathrm{mmol})$ damla damla ilave edildi. Ardından ortama yine DCM' de (5 mL) çözülmüş katalitik miktardaki dimetil amino piridin $(0,09 \mathrm{mmol})$ eklendi. 10 dakika bu sıcaklıkta karıștırıldıktan sonra (5 mL) DCM' de çözülmüş sekonder amin (2) $(1,85 \mathrm{mmol})$ damla damla ilave edildi sonrasında bir gece geri soğutucu altında kaynatıldı.
Daha sonra eter ile ekstraksiyon yapılıp organik fazın çözücüsü evaparatörde uçuruldu.

\section{Fenil (2-bromoallil)(furan-2- ilmethil)fosforamidokloridat (4b) :}

Diklorometan (DCM)' da (5mL) çözülmüş fenil dikloro fosfat $(2,74 \mathrm{mmol})$ üzerine $0^{\circ} \mathrm{C}^{\prime}$ de trietil amin $(8,25 \mathrm{mmol})$ damla damla ilave edildi. Ardından ortama yine DCM' de (5 mL) çözülmüş katalitik miktardaki dimetil amino piridin $(0,14 \mathrm{mmol})$ eklendi. 10 dakika bu sıcaklıkta karıştırıldıktan sonra (5 mL) DCM' de çözülmüş sekonder amin (2) (3,00 mmol) damla damla ilave edildi sonrasında bir gece geri soğutucu altında kaynatıldı. Daha sonra eter ile ekstraksiyon yapılıp organik fazın çözücüsü evaparatörde uçuruldu.

\subsubsection{Diels-alder halkalaşma reaksiyonları $(3 a, 3 b, 5 a, 5 b)$}

\section{Termal yöntem:}

Termal halkalaşma reaksiyonları başlangıç maddeleri 1a, 1b, 4a ve $\mathbf{4 b}$ nin toluen içerisinde geri soğutucu altında 4 gün boyunca kaynatılması sonucu gerçekleştirildi Daha sonra evaparatörde çözücüsü uçurulup kolon kromatografisi ile saflaştırıldı.

\section{Mikrodalga yöntem:}

$\mathrm{Bu}$ reaksiyonlar başlangıç maddeleri 1a, 1b, $\mathbf{4 a}$ ve $\mathbf{4 b}$ nin cam vialler içerisinde çözücüsüz ortamda maksimum 800 Watt güç üretebilen ticari bir mikrodalga fırında farklı süreler ve farklı güç seviyelerinde ısıtılarak yapıldı, sonuçlar ince tabaka kromatografisinde izlendi. 

Reaksiyonları

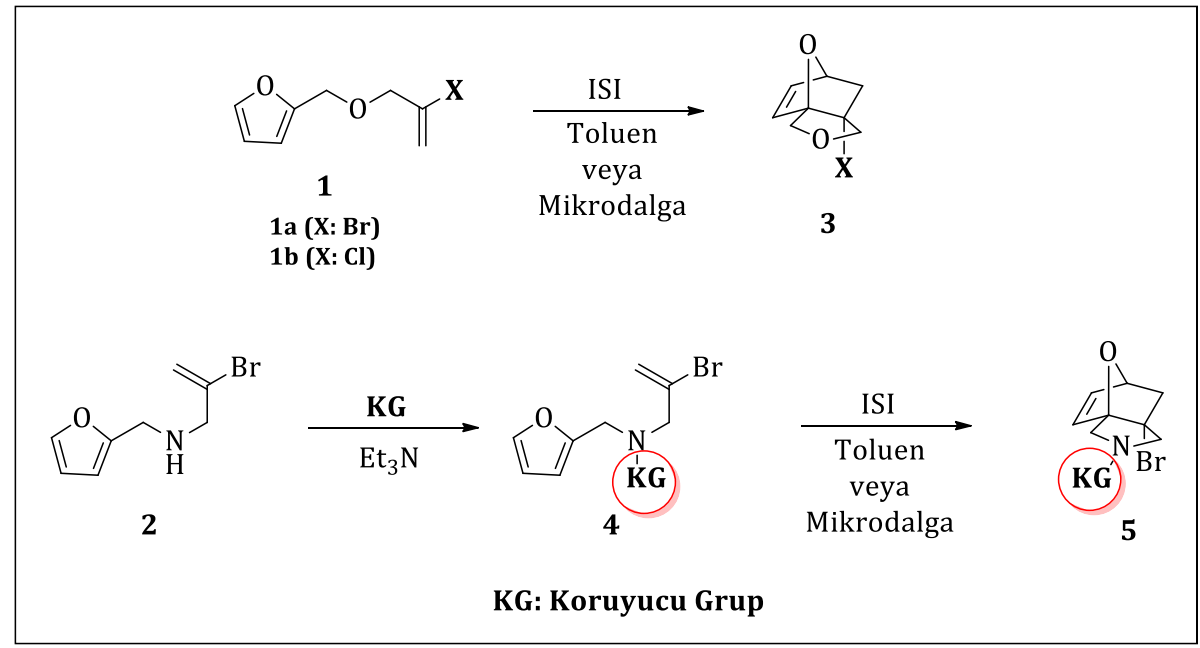

Şekil 2: Koruma ve halkalaşma reaksiyonları

\section{Bulgular}

\subsection{Sentezlenen Maddelerin Analiz Sonuçları}

\subsubsection{5-Bromo-3,10-dioksa- trisiklo[5.2.1.0*1,5*]dek-8-en (3a):}

Ürün renksiz yağımsı sıvı, (Termal verim $\% 15$ )

$v_{\max }$ (thin film) $/ \mathrm{cm}^{-1}$ : 2935(s, C-H), 1570 (s, C=C), 1230, 1050, 615 (z, C-Br). $\delta_{\mathrm{H}}\left(400 \mathrm{MHz} \mathrm{CDCl}_{3}\right): 6.50-6.46(\mathrm{~m}, 2 \mathrm{H})$, 5.16 (dd, $1 \mathrm{H}, J_{1} 1.5 \mathrm{~Hz}, J_{2} 4.5 \mathrm{~Hz}$ ), 4.51 (d, $1 \mathrm{H}, J 11.0 \mathrm{~Hz}, A B), 4.37$ (d, $1 \mathrm{H}, J 10.2 \mathrm{~Hz}$, $A B), 4.17(\mathrm{~d}, 1 \mathrm{H}, J 11.0 \mathrm{~Hz}, A B), 3.96(\mathrm{~d}, 1 \mathrm{H}$, $J 10.2 \mathrm{~Hz}, A B), 2.54\left(\mathrm{dd}, 1 \mathrm{H}, J_{1} 4.5 \mathrm{~Hz}, J_{2}\right.$ $12.5 \mathrm{~Hz}, A B), 1.74(\mathrm{~d}, 1 \mathrm{H}, J 12.5 \mathrm{~Hz}, A B)$. $\delta_{\mathrm{C}}\left(100 \mathrm{MHz} \mathrm{CDCl}_{3}\right): 138.7,136.4,101.5$ (q), 83.7, 83.2, 68.9, 68.6, 42.0.

\subsubsection{5-Kloro-3,10-dioksa- trisiklo[5.2.1.0*1,5*]dek-8-en (3b):}

Ürün renksiz yağımsı sıvı (Termal verim $\% 15$ )

$u_{\max }\left(\right.$ thin film) $/ \mathrm{cm}^{-1}: 2944(\mathrm{k}, \mathrm{C}-\mathrm{H}), 2876$ (k, C-H), 1251 (k, C-O), 774 (z, C-Cl). $\delta_{\mathrm{H}}\left(400 \mathrm{MHz} \mathrm{CDCl}_{3}\right): 6.57(\mathrm{~d}, 1 \mathrm{H}, J 5.8 \mathrm{~Hz}$, $A B), 6.53(\mathrm{~d}, 1 \mathrm{H}, J 5.6 \mathrm{~Hz}, A B), 5.16(\mathrm{dd}, 1 \mathrm{H}$, $\left.J_{1} 1.3 \mathrm{~Hz}, J_{2} 4.5 \mathrm{~Hz}\right), 4.50$ (d, $1 \mathrm{H}, J 11.0 \mathrm{~Hz}$,
$A B), 4.37(\mathrm{~d}, 1 \mathrm{H}, J 9.8 \mathrm{~Hz}, A B), 4.17(\mathrm{~d}, 1 \mathrm{H}$, $J 11.0 \mathrm{~Hz}, A B), 3.96(\mathrm{~d}, 1 \mathrm{H}, J 9.8 \mathrm{~Hz}, A B)$, $2.54\left(\mathrm{dd}, 1 \mathrm{H}, J_{1} 4.5 \mathrm{~Hz}, J_{2} 12.5 \mathrm{~Hz}, A B\right), 1.74$ (d, $1 \mathrm{H}, J 12.5 \mathrm{~Hz}, A B)$.

$\delta_{\mathrm{C}}\left(100 \mathrm{MHz} \mathrm{CDCl}_{3}\right): 138.8,136.4,101.5$ (q), 83.7, 83.3, 68.9, 68.6, 41.9.

\subsubsection{N-(2-bromoallil)-N-(furan-2- ilmetil)-P-fenilfosfonamidik klorür (4a) :}

Ürün sarı katı. (Verim \%95). $U_{\max }$ (thin film)/ $\mathrm{cm}^{-1}: 2916(\mathrm{k}, \mathrm{C}-\mathrm{H}), 1247$ (k, P=0), 881 (k, P-N), 690 (k, C-Br) $\delta_{\mathrm{H}}\left(400 \mathrm{MHz} \mathrm{CDCl}_{3}\right): 7,46-7,34(\mathrm{~m}, 5 \mathrm{H})$, $7,27(\mathrm{~d}, 1 \mathrm{H}, J 1,5 \mathrm{~Hz}) 6,65(\mathrm{~d}, 1 \mathrm{H}, J 3,0 \mathrm{~Hz})$, 6,33-6,34 (m, 1H), 5,71 (s, 1H), 5,57 (s, $1 \mathrm{H}), 4,32$ (s, 2H), 3,77 (s, 2H).

$\delta_{\mathrm{C}}\left(100 \mathrm{MHz} \mathrm{CDCl}_{3}\right): 144.3,138.4,132.4$, 131.6, 131.3, 131.2, 131.1, 128.4, 128.2, 121.2, 114.0, 111.4, 50.8, 41.6 .

\subsubsection{Fenil (2-bromoallil)(furan-2- ilmethil)fosforamidokloridat (4b) :}

Ürün sarımsı sıvı. (Verim \%80). $U_{\max }$ (thin film) $/ \mathrm{cm}^{-1}: 2925(\mathrm{k}, \mathrm{C}-\mathrm{H}), 1277$ (k, P=0), 899 (k, P-N), 687 (k, C-Br) $\delta_{\mathrm{H}}\left(500 \mathrm{MHz} \mathrm{CDCl}_{3}\right): 7,30(\mathrm{~d}, 1 \mathrm{H}, J 2,0 \mathrm{~Hz})$, 7,28-7,12 (m, 5H), 6,24 (dd, 1H, J $J_{1} 2,0 \mathrm{~Hz}$ $\left.J_{2} 3,0 \mathrm{~Hz}\right), 6,22(\mathrm{~d}, 1 \mathrm{H}, J 3,0 \mathrm{~Hz}), 5,35(\mathrm{~s}$, $2 \mathrm{H}), 4,41-4,20(\mathrm{~m}, 2 \mathrm{H}), 3,93-3,78(\mathrm{~m}, 2 \mathrm{H})$ 
$\delta c\left(125 \mathrm{MHz} \mathrm{CDCl}_{3}\right): 150.0,149.1,143.0$, $130.0,126.0,120.6,120.5,115.8,110.5$, $110.0,51.7,42.1$.

3.1.5. (7a-bromo-1,6,7,7a-tetrahidro3a,6-epoksiizoindol-2(3H)il)(fenil)fosfinik klorür (5a):

Ürün siyah katı. (Termal verim \%98) $\mathrm{U}_{\max }$ (thin film)/ $\mathrm{cm}^{-1}: 2955(\mathrm{k}, \mathrm{C}-\mathrm{H}), 2585$ (k, C-H), 1249 (k, P=O), 886 (k, P-N), 695 (k, C-Br)

$\delta_{\mathrm{H}}\left(500 \mathrm{MHz} \mathrm{CDCl}_{3}\right): 7,36-7,20(\mathrm{~m}, 5 \mathrm{H})$, 6,46(dd, $\left.1 \mathrm{H}, J_{1} 1,5 \mathrm{~Hz}, J_{2} 6,0 \mathrm{~Hz}\right), 6,38(\mathrm{~d}$, $1 \mathrm{H}, \mathrm{J} 6,0 \mathrm{~Hz}) 5,05-5,04(\mathrm{~m} 1 \mathrm{H}), 4,28(\mathrm{~s}, 2 \mathrm{H})$, $3.76,(\mathrm{~s}, 2 \mathrm{H}), 5.54-2.50(\mathrm{~m}, 2 \mathrm{H})$.
3.1.6. Fenil (7a-bromo-1,6,7,7atetrahidro-3a,6-epoksiizoindol-2(3H)yl)fosfonokloridat (5b):

Ürün sarı yağımsı sıvı. (Termal verim $\% 50$ )

$U_{\max }$ (thin film)/ $\mathrm{cm}^{-1}: 2905(\mathrm{k}, \mathrm{C}-\mathrm{H}), 2881$ (k, C-H), 1280 (k, P=0), 933 (k, P-N), 687 (k, C-Br)

$\delta_{\mathrm{H}}\left(500 \mathrm{MHz} \mathrm{CDCl}_{3}\right): 7,41-7,19(\mathrm{~m}, 5 \mathrm{H})$, $6,60(\mathrm{~d}, 1 \mathrm{H}, J 6,0 \mathrm{~Hz}), 6,50\left(\mathrm{dd}, 1 \mathrm{H}, J_{1} 6,0 \mathrm{~Hz}\right.$, $J_{2} 4,0 \mathrm{~Hz}$ ), 5,13 (d, 1H, J $4.0 \mathrm{~Hz}$ ), 4,13-4,09 (m, 2H), 3,86-3,81 (m, 1H), 3,65-3,60 (m, $1 \mathrm{H}), 2.59$ (dd, $2 \mathrm{H}, J_{1} 5,5 \mathrm{~Hz}, J_{2} 12,5 \mathrm{~Hz}$ )

$\delta_{\mathrm{c}}\left(125 \mathrm{MHz} \mathrm{CDCl}_{3}\right): 149.8,138.0,129.0$, 128.0, 125.3, 120.5, 120.4, 97.7, 81.2, 62.0, $47.0,41.3,41.1$.

\subsection{Mikrodalga Reaksiyon Verileri}

Tablo 1 Oksijen yan zincirli bileşiklerin mikrodalga reaksiyon verileri

\begin{tabular}{|c|c|c|c|c|}
\hline \multicolumn{3}{|c|}{$\begin{array}{c}1 \\
\text { 1a (X: Br) } \\
1 \mathrm{~b}(\mathrm{X}: \mathrm{Cl})\end{array}$} & \multicolumn{2}{|c|}{$\begin{array}{c}\text { 3 } \\
\text { 3a (X: Br) } \\
\text { 3b (X: Cl) }\end{array}$} \\
\hline Deneme no & Güç & Süre & Verim (1a:3a)* & Verim (1b:3b)* \\
\hline 1 & $400 \mathrm{~W}$ & 1 dak. & 100:0 & 100:0 \\
\hline 2 & $400 \mathrm{~W}$ & 5 dak. & 100:0 & 100:0 \\
\hline 3 & $400 \mathrm{~W}$ & 10 dak & $80: 20$ & $85: 15$ \\
\hline 4 & $400 \mathrm{~W}$ & 10 dak & $80: 20$ & $80: 20$ \\
\hline 5 & $600 \mathrm{~W}$ & 1 dak. & 100:0 & $100: 0$ \\
\hline 6 & $600 \mathrm{~W}$ & 5 dak. & $80: 20$ & $85: 15$ \\
\hline 7 & $600 \mathrm{~W}$ & 10 dak & $75: 25$ & $80: 20$ \\
\hline 8 & $600 \mathrm{~W}$ & 10 dak & $75: 25$ & $80: 20$ \\
\hline 9 & $600 \mathrm{~W}$ & 5 dak. & $80: 20$ & $85: 15$ \\
\hline 10 & $600 \mathrm{~W}$ & 10 dak & $75: 25$ & $80: 20$ \\
\hline
\end{tabular}

* Reaksiyona girmeyen açık zincirli yapı ile halkalı ürünün birbirine oranı 
Tablo 2 Fenil fosfonil diklorit koruyucu gruplu bileşiğin mikrodalga reaksiyon verileri

\begin{tabular}{|c|c|c|c|}
\hline \multicolumn{2}{|c|}{$4 a$} & \multicolumn{2}{|c|}{$5 a$} \\
\hline Deneme no & Güç & Süre & Verim (4a:5a)*a \\
\hline 1 & $600 \mathrm{~W}$ & 1 dak. & $100: 0$ \\
\hline 2 & $600 \mathrm{~W}$ & 5 dak. & $100: 0$ \\
\hline 3 & $600 \mathrm{~W}$ & 10 dak & $60: 5^{* b}$ \\
\hline 4 & $600 \mathrm{~W}$ & 10 dak & $60: 5^{* b}$ \\
\hline
\end{tabular}

*a Reaksiyona girmeyen açık zincirli yapı ile halkalı ürünün birbirine oranı

*b Yan ürünler meydana gelmiștir.

Tablo 3 Fenil dikloro fosfat koruyucu gruplu bileșiğin mikrodalga reaksiyon verileri

\begin{tabular}{|c|c|c|c|}
\hline \multicolumn{3}{|c|}{ Güç } & Süre \\
\hline Deneme no & $600 \mathrm{~W}$ & 1 dak. & $100: 0$ \\
\hline $\mathbf{1}$ & $600 \mathrm{~W}$ & 5 dak. & $75: 25$ \\
\hline $\mathbf{2}$ & $600 \mathrm{~W}$ & 10 dak & $50: 50$ \\
\hline $\mathbf{3}$ & $600 \mathrm{~W}$ & 10 dak & $50: 50$ \\
\hline $\mathbf{4}$ & &
\end{tabular}

* Reaksiyona girmeyen açık zincirli yapı ile halkalı ürünün birbirine oranı

\section{Tartışma ve Sonuç}

\subsection{Koruma İşlemi}

Furanlı bileşiklerin tethederinde azot kullanıldığ zaman alkilasyon ișlemi sonucundaki sekonder amin (2) halkalaşmamıştır. $\mathrm{Bu}$ nedenle sterik dayanak noktası olarak hacimce büyük aynı zamanda elektronik olarakta elektronegatif bir koruyucu grup olan fenil fosfonil diklorit ve fenil diklorofosfat kullanılarak başlangıç maddeleri korunarak 4 bileşikleri elde edilmiştir. (Şekil 2).
Reaksiyon $0^{\circ} \mathrm{C}$ sicaklıkta ve diklorometan (DCM) içinde gerçekleștirilmiştir.

Reaksiyonun ilk adımında $\mathrm{Et}_{3} \mathrm{~N}$, amin üzerindeki $\mathrm{H}$ atomunu alarak azot atomunu aktif hale getirmiș, ikinci adımda ise negatif yükle yüklenerek aktif hale gelen $\mathrm{N}$ atomu koruyucu gruptaki fosfor atomuna saldırarak bağlanmış ve klor açığa çıkmıştır.

IR spektrumunda 3300-3400 $\mathrm{cm}^{-1}$ 'deki tekli NH pikinin kaybolup $1200-1400 \mathrm{~cm}^{-}$ ${ }^{1}$ de $\mathrm{P}=0$ ve $700-900 \mathrm{~cm}^{-1}$ 'de $\mathrm{P}-\mathrm{N}$ pikinin gözlenmesi, yapı aydınlatılmasında kullanılan en belirleyici özelliktir. 


\subsection{Halkalaşma Reaksiyonu}

İntramoleküler diels Alder Halkalașma reaksiyonları inert atmosfer altında (argon veya azot gazı altında) termal olarak, Lewis asidi katalizörlüğünde $[5,11]$, basınç altında ve mikrodalga ışınları [12,13] ile gerçekleştirilebilirler. Yapılan halkalaşma reaksiyonları hem termal şartlarda $95-105{ }^{\circ} \mathrm{C}$ sicaklıkta toluen içerisinde, geri soğutucu yardımıyla 4 günde, hemde mikrodalga sentez yöntemi ile farklı sıcaklık ve zaman aralıklarında çözücüsüz ortamda gerçekleştirilmiştir. (Şekil 1).

Diels-Alder halkalaşma reaksiyonları sonucunda reaksiyona girmeyen başlangıç maddeleri kolon kromatografisi ile tekrar geri kazanılarak reaksiyon yeniden tekrarlanabilir. Böylece verim daha da arttırılabilir.

Halkalaşma mekanizmaları temelde aynı olmalarına rağmen oksijen yan zincirli alkilasyon ürünleri ile azot yan zincirli alkilasyon ürünlerinin halkalaşma verimleri farklıdır. Azot atomu, üzerindeki koruyucu guruptan dolayı büyük grup etkisi ile halkalaşmayı provoke ederken, oksijen atomları üzerlerindeki eșleşmemiș elektron çiftleri ile bir makas gibi davranarak, halkalaşma verimini arttırmaktadır.

Bunların yanı sıra kuarterner pozisyonda bir halojen atomunun bulunması halkalaşma eğilimini engelleyici yönde etkilemesine rağmen, halkalaşma işlemi gerçekleşmektedir.

Termal IMDA reaksiyonu exo-ara kademe üzerinden yürümekte olup, yapıda brom ve klor atomu sterik etki nedeni ile endo pozisyonunu (doğal olarak) tercih etmiștir. (Şekil 3).

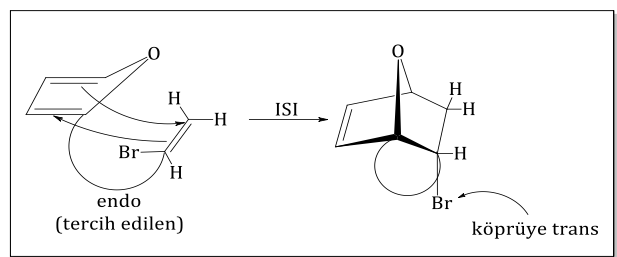

Şekil 3 Dienin dienofile yaklaşımı

Tablo 4 Mikrodalga ve termal reaksiyon karşılaștırma tablosu

\begin{tabular}{|c|l|l|l|l|l|l|}
\hline Reaksiyon & $\begin{array}{l}\text { Mikrodalga } \\
\text { Enerji } \\
\text { Miktarı }\end{array}$ & $\begin{array}{l}\text { Termal } \\
\text { Sıcaklık }\end{array}$ & $\begin{array}{l}\text { Mikro } \\
\text { dalga } \\
\text { Süre }\end{array}$ & $\begin{array}{l}\text { Termal } \\
\text { Süre }\end{array}$ & $\begin{array}{l}\text { Mikrodalga } \\
\text { Verim } \\
\text { (Açı yapı: } \\
\text { Halka) }\end{array}$ & $\begin{array}{l}\text { Termal } \\
\text { Verim } \\
\text { (Açı yapı: } \\
\text { Halka) }\end{array}$ \\
\hline $\begin{array}{c}\mathbf{1} \\
\mathbf{3 a})\end{array}$ & 600 Watt & $95-105^{\circ} \mathrm{C}$ & 10 dakika & 4 Gün & $75: 25$ & $85: 15$ \\
\hline $\begin{array}{c}\mathbf{2} \\
\mathbf{3 b}\end{array}$ & 600 Watt & $95-105^{\circ} \mathrm{C}$ & 10 dakika & 4 Gün & $80: 20$ & $85: 15$ \\
\hline $\begin{array}{c}\mathbf{3} \\
\mathbf{5 a}\end{array}$ & 600 Watt & $95-105^{\circ} \mathrm{C}$ & 10 dakika & 4 Gün & $60: 5$ & $2: 98$ \\
\hline $\begin{array}{c}\mathbf{5} \\
\mathbf{5 b}\end{array}$ & 600 Watt & $95-105^{\circ} \mathrm{C}$ & 10 dakika & 4 Gün & $50: 50$ & $50: 50$ \\
\hline
\end{tabular}

\subsection{Sonuçlar}

Yapılan halkalașma reaksiyonlarına göre Tablo 4 deki karşılaştırmalar sonucunda aşağıdaki sonuçlara ulaşılmıştır:

Mikrodalga yöntemle yapılan reaksiyonlarda hem sicaklık hemde zaman parametreleri değiştirilerek deneyler yapılmıștır. Elde edilen sonuçlara göre optimum şartların 600 Watt enerji ve 10 dakika süre olduğu sonucuna varılmıştır. $\mathrm{Bu}$ enerjinin ve sürenin altında verimlerin daha düşük olduğu görülürken daha yüksek enerjili (800 Watt) ve daha uzun sürelerde (20 
dak) maddede bozulmalar sonucunda istenmeyen yan ürünlerin oluştuğu gözlemlenmiştir.

1 numaralı reaksiyonda verim kayda değer bir artış gösterirken (\% 15 den \% 20 ye artış) 2 numaralı reaksiyonlarda fazla bir verim artışı gözlenmemiștir. Bunun yanı sıra 4 numaralı reaksiyon ise termal yöntemle aynı ölçüde bir halkalaşma verimine sahip olduğu bulunmuştur.

Yan zincirde halojenli olan yapılarda Bromlu maddeler Klorlu maddelere göre mikrodalga da daha çok halkalaşma eğilimi göstermiștir.

İlginç bir şekilde 3 numaralı reaksiyon termal olarak çok yüksek verimde gerçekleşirken mikrodalga yöntemde çok az halkalaşmış ve yan ürünler meydana gelmiştir. Bunun sebebi olarak maddenin mikrodalga yöntemle halkalaşmadan bozulmasından kaynaklandığı sonucuna varılmıştır.

Tablo 1 de gösterilen oksijen yan köprülü reaksiyonlarda 9 . ve 10 . denemeler Lewis Asit katalizörü olan $\mathrm{AlCl}_{3}$ varlığında gerçekleştirilmiş. Reaksiyon sonucunda halkalaşma verimleri aynı kalmış fakat istenmeyen yan ürün miktarı artmıştır.

Sonuç olarak termal ve mikrodalga halkalaşma reaksiyonlarının sonuçları karşılaştırıldığında mikrodalga yöntem ile yapılan reaksiyonlar halkalaşma ürünleri açısından termal reaksiyonlarla karşılaştırılabilir nitelikte olduğu görülmüştür.

Reaksiyonların çözücüsüz ortamda gerçekleşmesi, çok düşük miktarlarda maddelerle çalışılması, süre olarak karşılaştırılamayacak kadar kısa sürede reaksiyonların oluşması, çevreye duyarlı ve yeşil kimyaya katkılı bir yöntem olduğunu kanıtlamaktadır.
Ayrıca kontrollü olarak isıtıldığında termal reaksiyonlarla aynı hatta bazı durumlarda daha yüksek verimlerde ürün elde edilmesi açısından, mikrodalga reaksiyon yöntemleri molekül içi Diels-Alder halkalaşma reaksiyonlarında avantaj sağlamaktadır.

\section{Teşekkür}

Aksaray Üniversitesi Rektörlüğü Bilimsel Araştırma Projeleri Birimine sağlamış oldukları destek ve yardımlardan dolayı teşekkür ederiz. (Proje No: 2015-047)

\section{Kaynakça}

[1] Hong, X., Mejia-Oneto, J.M., Padwa, A. 2006. Teterahedron Lett., 47,8387 .

DOI: 10.1016/j.tetlet.2006.09.071.; Hong, X., Mejia-Oneto, J.M., France, S., Padwa, A. 2006. Teterahedron Lett., 47, 2409.

DOI: 10.1016/j.tetlet.2006.01.152.; Padwa, A. 2005. J. Org. Met. Chem., 690, 5533. DOI: 10.1016/j. jorganchem.2005.06.010; Padwa, A., Nara, S., Wang, Q. 2006. Tetrahedron Lett., 47, 595.

DOI: 10.1016/j.tetlet.2005.11.026.; Namboothiri, I.N.N., Ganesh, M., Mobin, S.M., Cojocaru, M. 2005. J. Org. Chem., 70, 2235. DOI: 10.1021/jo048262x.; Padwa, A., Crawford, K.R., Straub, S.C., Pieniazek, S.N., Houk, K.N. 2006. J. Org. Chem., 71, 5432. DOI: 10.1021/jo0602322. ; Padwa, A., Wang, Q. 2006. J. Org. Chem., 71, 3210. DOI: $10.1021 /$ jo051550o.

[2] Paulvannan, K. 2004. J. Org. Chem., 69, 1207-1214. DOI: $10.1021 /$ jo030231z.

[3] Mance, A.D., Jakopcic, K. 2005. Molecular Diversity., 9, 1-3, 229-21. DOI: $10.1007 / s 11030-005-3434-8$.

[4] Read, M.L., Gundersen, L.L. 2013. J. Org. Chem., 78 (3), 1311-1316. DOI: 10.1021/jo3027033. 
M. Karaarslan/ Furan Çekirdekli Bileşiklerin Mikrodalga Destekli Molekül İçi Diels Alder Halkalaşma Reaksiyonları

[5] Prajapati, D., Laskar, D.D., Sandhu, J. S. 2000. Tetrahedron Lett., 41, 8639-8643.

DOI:10.1016/S0040-4039(00) 01513-6.

[6] Huang, H.L., Huang, H.C., Liu, R.S. 2002. Tetrahedron Lett., 43, 7983. DOI:10.1016/S0040-4039 (02)01815-4

[7] Choony, N., Dadabhoy, A., Sammes, P.G. 1998. J. Chem. Soc., 1, 20172021. DOI: $10.1039 / a 802415 d$.

[8] Parrill, A.L., Dolata, D.P. 1994. Tetrahedron Lett., 35, 7319-7322. DOI:10.1016/0040-4039 (94)85303-7.
[9] Demircan, A., Karaarslan, M., Turac, E. 2006. Heterocyclic Commun., 12(3-4), 233-240.

[10] Karaarslan, M., Demircan, A., 2007. Asian Journal of Chemistry, 19, 4, 2999-3006.

[11] Rogers, C., Keay, B.A. 1992. J. Chem., 70, 2929. DOI: $10.1139 / \mathrm{v} 92-375$.

[12] Smith, D.A., Houk, K.N. 1991. Tetrahedron Lett., 32, 1549-1552. DOI:10.1016/S0040-4039 (00)74269-9

[13] Crawford, K.R., Bur, S.K., Straub, C.S., Padwa, A. 2003. Org. Lett., 5, 3337-3340.

DOI: $10.1021 / \mathrm{ol} 035233 \mathrm{k}$. 